WellBeing International

WBI Studies Repository

$3-22-2000$

\title{
Floor Temperature Preference of Sows at Farrowing
}

P. A. Phillips

Agriculture and Agri-Food Canada

D. Fraser

University of British Columbia, dfraser@mail.ubc.ca

B. Pawluczuk

Agriculture and Agri-Food Canada

Follow this and additional works at: https://www.wellbeingintlstudiesrepository.org/houcfani

Part of the Agribusiness Commons, Animal Studies Commons, and the Operations and Supply Chain Management Commons

\section{Recommended Citation}

Phillips, P. A., Fraser, D., \& Pawluczuk, B. (2000). Floor temperature preference of sows at farrowing. Applied Animal Behaviour Science, 67(1), 59-65.

This material is brought to you for free and open access by WellBeing International. It has been accepted for inclusion by an authorized administrator of the WBI Studies Repository. For more information, please contact wbisr-info@wellbeingintl.org.

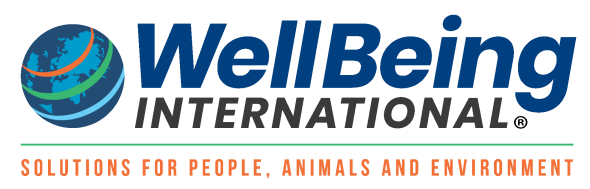




\title{
Floor Temperature Preference of Sows at Farrowing
}

\author{
P.A. Phillips ${ }^{1}$, D. Fraser ${ }^{2}$, B. Pawluczuk ${ }^{1}$ \\ ${ }^{1}$ Agriculture and Agri-Food Canada \\ ${ }^{2}$ University of British Columbia
}

\begin{abstract}
KEYWORDS
sow, parturition, farrowing crate, thermoregulation, floor temperature, environmental preference

ABSTRACT

A preference testing apparatus was used to provide sows with continuous access to three identical farrowing crates, each with a different floor temperature. The concrete floor under each crate contained copper pipe through which temperature-controlled water was circulated to achieve unoccupied floor temperatures of $22^{\circ} \mathrm{C}( \pm 3.5), 29^{\circ} \mathrm{C}( \pm 1)$ and $35^{\circ} \mathrm{C}( \pm 1)$. Eighteen sows were tested in the apparatus. Video recording was used to determine sow position from 7 days before farrowing (Days -7 to -1 ) to 14 days after (Days 1 to 14). On Days -7 to -1 , sows showed no significant preference among the three temperatures when selecting a resting area. Once farrowing had begun, there was a significant increase $(P<0.01)$ in the use of the $35^{\circ} \mathrm{C}$ floor and it became the most preferred resting area for Days 1 to 3 . After this interval, use of the $35^{\circ} \mathrm{C}$ floor declined significantly $(P<0.01)$, and use of the cooler floors increased, resulting in no significant thermal preference during Days 4 to 6 . There was a further decline in the use of the $35^{\circ} \mathrm{C}$ floor after Days 4 to $6(P<0.01)$ to the extent that the coolest floor $\left(22^{\circ} \mathrm{C}\right)$ became the most preferred from Days 7 to 14. In summary, sows showed a pronounced increase in preference for a warm floor during the 3 days after the start of farrowing. This change in preference may explain how free-living sows select a suitable thermal environment for their young, and why sows try to avoid metal flooring at the time of farrowing.
\end{abstract}

\section{Introduction}

The use of farrowing crates and the absence of bedding in farrowing houses greatly restricts the ability of sows to select or create a suitable micro-climate for themselves and their litters. Consequently, equipment design and animal management must be well suited to the animals to compensate for the lack of behavioural options. A suitable thermal environment is especially difficult to achieve in the farrowing house because the environmental needs of the sow and litter are quite different.

While considerable technical knowledge is available on feeding management of the sow and the control of piglet environment, little attention has been given to the environmental preferences of the sow beyond matters that concern feed intake. For example, snout and mist cooling systems have evolved as a means 
to increase sow feed intake, which becomes depressed in hot weather. We have reported a series of preference tests aimed at identifying aspects of farrowing crate environment that appear significant to sows (Phillips et. al., 1991, 1992, 1996). Knowledge of these preferences could lead to improvements in facility design that might benefit productivity and welfare of sows.

Phillips et. al. (1996) found that sows, even when well adapted to using metal flooring, avoided metal in favour of concrete or plastic-coated flooring around the time of parturition. One possible reason for this rejection is that the metal, being a thermal conductor, feels cold to the udder. Evidence from other studies suggests that the sow is attracted to warmth around the time of farrowing (Titterington and Fraser, 1975; Gravås, 1979). This study was designed to provide more information on sows' floor temperature preferences, and to test whether preference for warm flooring increases around the time of farrowing.

\section{Materials and methods}

\subsection{Test apparatus}

The test apparatus offered individual sows free access to three identical farrowing crates, each $1.5 \mathrm{~m}$ long and $0.6 \mathrm{~m}$ wide, radiating from a central hub area sufficiently large to allow sows to exit from one crate and move freely into another (see illustration in Phillips et al., 1991). Each crate was equipped with a feeder at the front. Between the three crates were three triangular creep areas accessible to the piglets. These were covered in rubber mat and heated with radiant heat lamps overhead. The apparatus was mounted on a platform $0.3 \mathrm{~m}$ above the floor and was located in a temperature-controlled room (24 \pm $\left.38^{\circ}\right)$.

The floor of each crate consisted of a concrete panel, each $0.76 \times 1.85 \mathrm{~m}$, constructed so that floor temperature could be held at either $35 \pm 1^{\circ} \mathrm{C}$ (chosen to represent approximate sow skin temperature), 22 $\pm 3.5^{\circ} \mathrm{C}$ (approximate room temperature), or $29 \pm 1^{\circ} \mathrm{C}$ (an intermediate temperature). Each floor panel was embedded with $13 \mathrm{~mm}$ diameter copper pipe with U-connectors at alternate ends to form $17 \mathrm{~m}$ long continuous coil within the concrete. The pipe was laid parallel to the long axis of the crate at about $75 \mathrm{~mm}$ on-centre. Two thermocouples were embedded in the concrete near the middle of each panel to monitor floor temperature. Concrete was poured around the coil to a depth of $5 \mathrm{~cm}$ and was finished with a wood float. Thermostatically controlled, heated water baths with submersible pumps were used to maintain two of the floor panels at temperatures of $35 \pm 1^{\circ} \mathrm{C}$ and $29 \pm 1{ }^{\circ} \mathrm{C}$. For the third floor panel (mean temperature $22 \pm 3.5^{\circ} \mathrm{C}$ ), water was supplied to the copper coil continuously by two methods. For the first five sows, water was supplied from a 20-1 reservoir located in the room. Because of occasional problems with temperature control, this method was discontinued after five sows, in favour of drawing small flows from the farm water supply (a deep well). While this method improved thermal stability, floor temperatures were typically $1-2^{\circ} \mathrm{C}$ cooler than the previous. To protect against possible position effects in the room, each treatment was offered an equal number of times in each of the three crate positions.

\subsection{Animals and procedures}

Eighteen Yorkshire and Yorkshire $\times$ Landrace sows of second and third parity were used. Each sow was brought from a concrete-floored gestation room to the testing apparatus 9 days before farrowing was due and remained in the test apparatus until 14 days after farrowing.

Throughout this time, the sow's use of the different crates was monitored by time-lapse video recording using an overhead camera at a rate of 1 frame every 3 min (480 observations/day). An extra camera was used to record the seven thermocouple display outputs (two thermocouples per floor plus room temperature). The records included the sow's location (in one of the crates or central area) and posture recorded as either active (standing or sitting) or lying. Observations were combined into five periods, 
which reflected general changes in the amount of sow activity: the $144 \mathrm{~h}$ ending $24 \mathrm{~h}$ before farrowing began (Days -7 to -2 ), the $24-\mathrm{h}$ period immediately before the start of farrowing (Day -1 ), the two $72-\mathrm{h}$ periods after farrowing (Days 1 to 3, Days 4 to 6), and the subsequent $168 \mathrm{~h}$ (Days 7 to 14). Time 0 was taken as the first video frame showing a newborn piglet. Active and lying behaviour were calculated daily for each period.

Daily feed allowance consisted of $3 \mathrm{~kg} /$ day until after farrowing and a larger amount (equal to the sow's estimated ad libitum intake) thereafter. This daily allowance was divided equally among the three feeders, to encourage sows to move to all areas of the preference testing apparatus each day.

\subsection{Data analysis}

The sows were active for only $15 \%$ of the time, and the feeding method required them to be active in all three crates. Consequently, the sows' use of the crates while active was not considered a valid indication of floor preference, and the analysis focused on the time that the sows spent lying on each floor. For each sow and each period, the number of frames in which the sow was lying in each of the three crates was expressed as a percentage of the total number of frames in which the sow was lying in all three crates combined. Three sows selected the centre of the apparatus as the most preferred lying site during a total of seven periods out of the 90 (18 sows $\times 5$ periods), which made up the experiment. These data were omitted from the analysis, as were data from one sow during Days 4-6 when room temperature often exceeded $27^{\circ} \mathrm{C}$.

Non-parametric analyses (Siegel, 1956) were used because the data were highly non-normal in distribution. Friedman's analysis of variance of ranks was used for overall comparisons of the three floor temperatures. Two-way comparisons were done using the Wilcoxon matched-pairs signed-ranks test to compare the same animals' responses at different times. Because a number of comparisons were done, a significance level of 0.01 was used. The Mann-Whitney U-test was used to compare the response of sows tested before and after the change in the method of producing the unheated control.

\section{Results}

Lying time on the $22^{\circ} \mathrm{C}$ floor did not differ significantly between sows $1-5$ and sows $6-18$, and there was no evidence of a preference for any of the three crate positions in the room in any of the periods. Hence, data were pooled for the different sows and crate positions.

The percentage of time that the sows were active (standing or sitting) followed a characteristic pattern (Phillips et al., 1996), with a sharp increase in activity from a mean of $15 \%$ during Days -7 to -2 , up to $35 \%$ during the $24 \mathrm{~h}$ before farrowing began (Day -1 ). The intense activity during this $24-\mathrm{h}$ period included frequent posture changes and frequent and relatively equal movement among all three treatments. After the start of farrowing, activity dropped sharply to $9 \%$ on Days 1 to 3 , then increased to $13 \%$ during Days 4 to 6, and returned to the pre-farrowing level of $15 \%$ on Days 7 to 14 .

During Days -7 to -1 , sows showed no significant preference for any floor temperature (Fig. 1). Once farrowing had begun, there was a significant increase in lying on the $35^{\circ} \mathrm{C}$ floor $(P<0.01)$. Treatment effect was significant for Days 1 to $3(P<0.01)$, with the $35^{\circ} \mathrm{C}$ floor being the most preferred (Fig. 1). Only five of 16 sows chose $35^{\circ} \mathrm{C}$ as most preferred on Day -1 , but this had risen to 11 of 16 during Days 1 to 3. Of the other five sows, one used the $35^{\circ} \mathrm{C}$ floor $90 \%$ of Day 1 but moved afterward, one preferred the other heated floor, one used all three crates about equally, and two preferred the $22^{\circ} \mathrm{C}$ floor. After this period, there was a significant decline $(P<0.01)$ in use of the $35^{\circ} \mathrm{C}$ floor and corresponding increases in use of the other floors. This resulted in there being no significant preferences among temperature treatments for Days 4 to 6 . After this period, the decline in resting on the $35^{\circ} \mathrm{C}$ floor continued $(P<0.01)$ 
resulting in a significant treatment effect on Days 7 to $14(P<0.01)$, with the $22^{\circ} \mathrm{C}$ floor being the most preferred. At this time, only one of 17 sows continued to use the $35^{\circ} \mathrm{C}$ floor as the most preferred option.

Fig. 1. Mean percent of lying time spent on each temperature treatment during five intervals from 7 days before farrowing until 14 days after. Standard error of the means is approximately $6 \%( \pm 1.5)$.

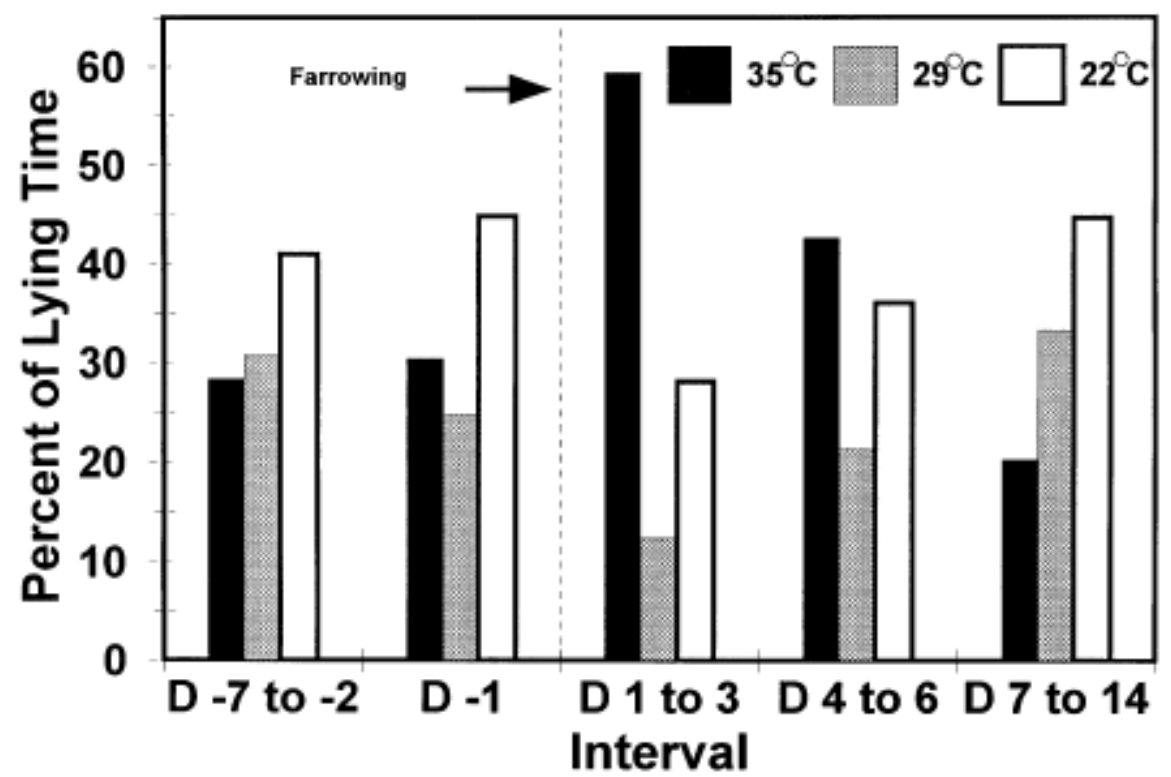

Fig. 2. The transient thermal response of the three floor treatments during the 60 min after a sow first lies on the floor (left) and during the $60 \mathrm{~min}$ after the sow stands up again (right). Each set of points is one occurrence of a sow lying down or standing up.

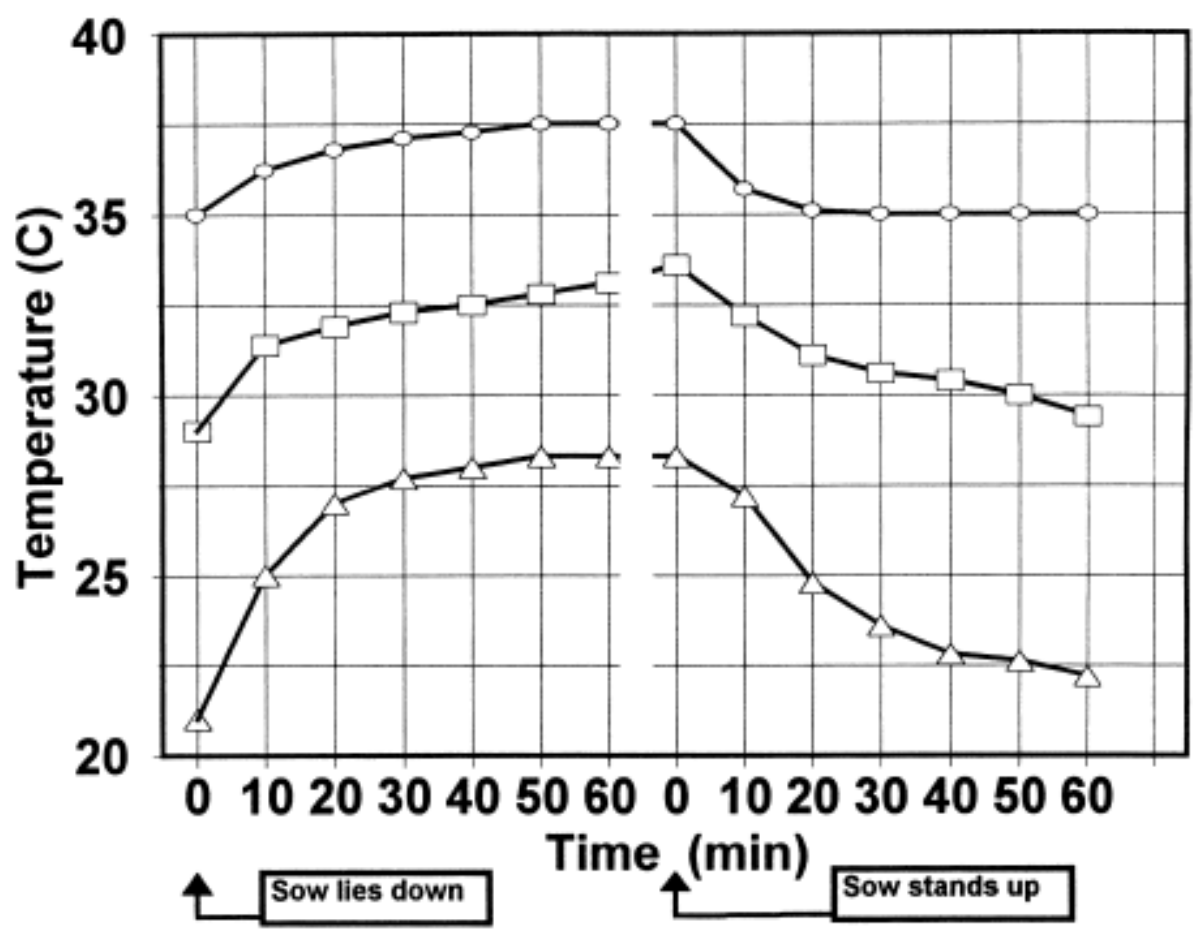


The sows created an unavoidable effect on floor temperature. Once a sow lay on a particular floor, the floor temperature was affected for the duration of its stay and for a time after she moved (Fig. 2). The floor returned to within $3^{\circ} \mathrm{C}$ of its designated temperature within about 20 min of the sow standing up.

\section{Discussion}

During the day before farrowing, sows show a pronounced motivation to find a secluded site and prepare a nest with insulating material (Jensen, 1986, 1993). This likely promotes the health and survival of piglets in nature, as piglets have a remarkably high requirement for warmth. For domestic piglets in a production situation, the lower critical temperature is about $34^{\circ} \mathrm{C}$ (Curtis, 1983), and a room temperature of $18-20^{\circ} \mathrm{C}$ is cool enough to depress rectal temperature and colostrum intake of newborn piglets (Le Dividich and Noblet, 1981). However, the piglets' need for warmth creates a problem for the sow, because her own thermal comfort zone is generally much lower, with the lower limit estimated at about $18-20^{\circ} \mathrm{C}$ by Curtis (1983). Thus, to create an optimal environment for the piglets, the sow must select or create an environment for farrowing that is well above the temperature that it would normally be expected to prefer.

The present results suggest how this may occur. During the time of farrowing, and for several days thereafter, the sows showed a clear change in their preferred floor temperature, with most animals selecting the warmest option of $35^{\circ} \mathrm{C}$. Sows commonly show an increase in body (rectal) temperature around the time of parturition (King et al., 1972; Hendrix et al., 1978; Kelley and Curtis, 1978). Moreover, with the enlargement of the udder and intense metabolic activity of early lactation, the udder surface becomes warmer (Fiala and Hurnik, 1983). Perhaps the sows are simply selecting a floor that does not feel cool on the newly warm udder surface, and this equips them in avoiding temperatures that would be too cool for the young.

The pronounced change in temperature preference may explain why sows in the first days after farrowing tend to lie with the udder facing a source of radiant heat (Titterington and Fraser, 1975; Gravås, 1979). This may also explain our previous finding that sows in environmental preference tests tend to move off perforated metal flooring in favour of perforated plastic or solid concrete flooring, for the few days during and soon after farrowing. Since metal is a thermal conductor, it may feel particularly cool on the udder and it may be avoided for this reason.

Effective farrowing room temperature will vary considerably on commercial farms. In general, warmer conditions would likely diminish the animal's preference for very warm floors, while cooler environments would likely make the heated floor options even more attractive to the sow. In addition, in this study, radiant heat lamps were positioned well away from the sow resting areas. This is a recommended practice on commercial farms as the sow does not need the heat and the heat lamp is meant to provide a safe, warm area for the pigs away from the sow. The results here, for the most part, support this practice. However, it would appear that for a few days during farrowing, the sow may actually be quite tolerant of a heat lamp that normally would be considered too close.

The practical implications of this result require further research. The fact that most sows selected warm flooring during and soon after farrowing does not necessarily mean that the cooler options were aversive (see Fraser et al., 1993). Moreover, because sows help to warm the floor on which they are lying, any discomfort from a cool floor may be short-lived. This could explain why two of the sows selected the $22^{\circ} \mathrm{C}$ floor even at farrowing. On the other hand, if sows that are required to farrow on cool or metal floors perceive these to be uncomfortable, then this discomfort might contribute to the agitation and restless activity. Such activity, which is sometimes seen at farrowing, may be responsible for some piglet deaths by crushing or savaging. 


\section{References}

Curtis, S.E., 1983. Environment Management in Animal Agriculture. The lowa State Univ. Press, Ames, IA.

Fiala, S., Hurnik, J.F., 1983. Infrared scanning of cattle and swine. Can. J. Anim. Sci. 63, 1008, (Abstr.).

Fraser, D., Phillips, P.A., Thompson, B.K., 1993. Environmental preference testing to assess the wellbeing of animals - an evolving paradigm. J. Agric. Environ. Ethics 6 (Suppl. 2), 104-114.

Gravås, L., 1979. Behavioural and physical effects of flooring on piglets and sows. Appl. Anim. Ethol. 5, 333-345.

Hendrix, W.F., Kelley, K.W., Gaskins, C.T., Bendel, R.B., 1978. Changes in respiratory rate and rectal temperature of swine near parturition. J. Anim. Sci. 47, 188-191.

Jensen, P., 1986. Observations on the maternal behaviour of free-ranging domestic pigs. Appl. Anim. Behav. Sci. 16, 131-142.

Jensen, P., 1993. Nest building in domestic sows: the role of external stimuli. Anim. Behav. 45, 351-358.

Kelley, K.W., Curtis, S.E., 1978. Effects of heat stress on rectal temperature, respiratory rate and activity in peripartal sows and gilts. J. Anim. Sci. 46, 357-361.

King, G.J., Wiloughby, R.A., Hacker, R.R., 1972. Fluctuations in rectal temperature of swine at parturition. Can. Vet. J. 13, 72-74.

Le Dividich, J., Noblet, J., 1981. Colostrum intake and thermoregulation in the neonatal pig in relation to environmental temperature. Biol. Neonate 40, 167-174.

Phillips, P.A., Fraser, D., Thompson, B.K., 1991. Preference by sows for a partially enclosed farrowing crate. Appl. Anim. Behav. Sci. 32, 35-43.

Phillips, P.A., Fraser, D., Thompson, B.K., 1992. Sow preference for farrowing-crate width. Can. J. Anim. Sci. 72, 740-745.

Phillips, P.A., Fraser, D., Thompson, B.K., 1996. Sow preference for flooring type in farrowing crates. Can. J. Anim. Sci. 76, 485-489.

Siegel, S., 1956. Nonparametric Statistics for the Behavioural Sciences. McGraw-Hill, New York, NY.

Titterington, R.W., Fraser, D., 1975. The lying behaviour of sows and piglets during early lactation in relation to the position of the creep heater. Appl. Anim. Ethol. 2, 47-53. 